\title{
STUDIES ON THE VASCULAR ARCHITECTURE AND THE FLUID EXCHANGE IN THE RABBIT POPLITEAL LYMPH NODE
}

\author{
JUNYA FUKUDA \\ Department of Pathology, School of Medicine, \\ Keio University, Tolyo, Japan \\ (Received for publication February 8, 1968)
}

\section{INTRODUCTION}

It is a widely acknowledged concept that lymphocytes are immunologically competent cells and lymph nodes are one of the antibody producing organs. The significance of lymphocytes and antigens hematogenously and lymphogenously transported to lymph nodes in various immune reactions must be understood in association with the structure and function of lymph nodes.

Our present knowledge concerning the structure and function of lymph nodes was mainly obtained from the works on the static aspects of the structure and function of lymphocytes, reticuloendothelial cells, and reticular tissue constituting the lymph node. Studies of the lymph node on the basis of organ nathology have been directed mainly to the analysis of interrelations between lymphocvtes, reticular cells and sinus system. The primary importance was put on the lymph flow or lymphogenous stimuli in various reactions of the nodes, while the role of the vascular system has been remained unemphasized.

Although embryologically lymph nodes develope from the wall of lymphatic vessel (Ando 1930), ${ }^{1}$ it seems that what makes up of the basic structure of the nodes is their blood vessel system as well as lymphatic sinus system. This view has been mentioned elsewhere (Iijima 1966). ${ }^{2}$

The author and the colleagues of this laboratory 3-18 have studied various problems of the microcirculation of the mesentery and the omentum of guinea pigs with in vivo observation methods for the past several years. In these studies we emphasized that not only blood circulation but also lymphatic system and the interrelations between both were taking important role in the formation of patho- 
logic features in those tissues.

On this basis, the effort must be paid for the first time to understand the structure and function of lymph nodes exactly. ${ }^{19-23}$ However, lymph nodes are thought to be in immature state of differentiation as an organ being compared with more differentiated organs such as lungs, livers, and kidneys. For this reason, lymph nodes seem to show remarkably wide deviation both in physiologic and pathologic conditions and this makes difficult to understand the structure and function of the lymph nodes.

In this paper, the vascular system of lymph nodes and the function of each part of blood vessel system, especially that of post-capillary venules, are investigated concerning with the lymph flow and fluid exchanges in lymph nodes. The author believes that these results would be of some help to study basic problems of various immune reactions.

\section{The microcirculatory architecture of the rabbit popliteal lymph node}

\section{Materials and Methods}

Animals used were albino rabbits of both sexes weighing approximately $2.5 \mathrm{~kg}$. The solution composed of 10 volume of $5 \%$ gelatin solution and 3 volume of india ink was warmed to 37 degrees C. Under ether anesthesia, $100 \mathrm{ml}$ of the solution prepared as described above was injected into the femoral artery of each rabbit through polyethylene catheter. After injection, the rabbit popliteal lymph nodes were removed, fixed in $10 \%$ formalin solution, embedded in paraffin, and made to 10 and 300 micron serial sections. Ten micron sections were stained with hematoxylin and eosin, and 300 micron sections cleared with xylene. Consecutive sections were cut at 10 and 300 micron alternately and successive two sections were compared.

\section{Results}

The afferent artery enters the hilus of the popliteal lymph nodes. Near the hilus it divides into a few branches toward the capsule. In the lymph nodes arteries pass straightly along the medullary cords and reach the cortical lymphatic matrix (Figs. 3, 7 and 8). And the arteries go straight through it, forming particularly dense networks of capillaries at the peripheral parts of the matrix where they face on the lymphatic sinuses. These capillary networks are distributed diffusely, forming complicate anastomoses at the peripheral areas of the matrix including the secondary nodules and medullary cords (Figs. 4 and 5). 
Arterioles branched out of arteries in the matrix enter the secondary nodules from the pole of the medullary side. In each secondary nodule capillary network is formed showing as a glomerulus-like pattern (Figs. 6 and 7).

These capillaries of the peripheral areas of lymphatic matrix including the secondary nodules and the medullary cords are collected toward the post-capillary venules (Figs. 6 and 7 ).

In the hematoxylin and eosin stained sections, post-capillary venules are lined by high cuboidal or cylindrical endothelia. The lumens of post-capillary venules become partially narrow because of their high endothelia. Lymphocytes are often seen in the interendothelial gaps and subendothelial spaces (Fig. 8). In sections with silver impregnation, the post-capillary venules are intertwined with several layers of reticular fibers.

The post-capillary venules form the venous plexuses in the cortical matrix. When secondary nodules are formed at almost every corner of the peripheral areas of the cortical lymphatic matrix, these venous plexuses are compressed to the small area, while the plexuses occupy the wide and larger zone when secondery nodules are very few or none (Figs. 9, 10, 11, 12, 13, 14 and Diag. 1).

The lymphatic matrix washed away by capillaries which branched from the terminal arterioles is evaluated as a functional unit. And the post-capillary venules which belong to these units gather to larger venules and leave from the hilus of lymph nodes as one or two efferent veins.

The details of the transition to venules from post-capillary venules are not exactly obious yet. The endothelia of the post-capillary venules gradually lower in transition to succeeding venules. ${ }^{22}$

2. The vascular system of the rabbit lymph node appreciated from ontogenic development

\section{Materials and Methods}

In the 15th and 25th day stage of fetus and 2nd and 5th day new-born rabbit, mesenterial, cervical and popliteal lymph nodes were studied. They were fixed in $10 \%$ formlin solution, embeded in paraffin, made 5 micron serial sections, stained with hematoxylin and eosin, and investigated with a light microscope.

\section{Results}

In the 15th day fetus, the lymph nodes have no clear capsule and their blood and lymphatic vessels are compricatedly entwined each other. There are mesenchymal cells including a few lymphocytes among them. However definite 
differentiation of each functional part of lymph nodes such as cortex, medulla and so on, is not yet shown.

In the 25th day fetus the accumulation of lymphocytes is somewhat increased. The capsule of the node is already formed. The post-capillary venules are not appeared (Fig. 15).

In the second day after birth the differentiation between the cortex and the medulla of the lymph node is clearly made and some of the blood vessels of the cortical matrix has high cuboidal endothelia (Fig. 16).

After this stage the post-capillary venule is able to be observed.

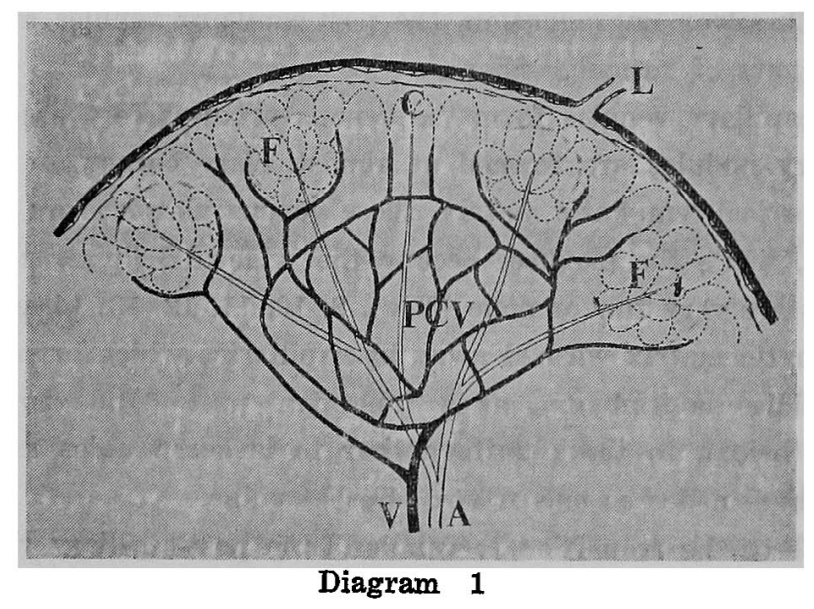

3. The passage of several substances from the lymphatic to the blood vessel in the rabbit popliteal lymph node

\section{Materials and Methods}

Albino rabbits of both sexes weighing approximately $2.5 \mathrm{~kg}$ were used. A polyethylen catheter (A), which measured $0.2 \mathrm{~cm}$ in diameter, was inserted into the afferent lymphatic of the popliteal lymph node of ether anesthesized animals under observation with an operation microscope so that the tip of the catheter reached 1 to $2 \mathrm{~cm}$ away from the lymph node (Fig. 17). At the same time similar catheter (B) as used above was inserted into the efferent vein to collect draining venous blood to the centrifuge tube. Then all confluent branches of draining veins from the node to the site inserted the catheter (B) were tighted to insure that the blood obtained came only from the popliteal lymph node (Fig. 17).

After 1 to $2 \mathrm{ml}$ of venous blood was collected from the catheter (B) as con- 
trol, several substances were introduced through the catheter (A). Venous blood draining the popliteal lymph nodes was collected at the interval of 10 to 15 minutes during the period of two hours after the introduction.

One to $2 \%$ pontamine sky blue in Ringer's solution, human whole sesa as an example of heterologous protein, and human gamma globulin (Globulin B Bank) were introduced into the afferent lymphatic of popliteal lymph nodes to prove the transference of these substances from the lymphatic to blood vessel within the lymph nodes.

One $\mathrm{ml}$ of each substance was usually introduced for 10 minutes. It seemed that the stimmulation caused by introduction of these various substances did not excess over physiologic range, because the dilatation of the afferent lymphatics or disorder of the movement of the lymphatic valves was not found and movement of efferent lymphatics showed the same behaviour as that of the dye injection into the subcutaneous tissue of the foot according to the observation with an operation microscope. The venous blood collected was centrifuged at $2000 \mathrm{rpm}$ during 10 minutes.

Sera obtained were examined as follows: Presence of pontamine sky blue in the sera was judged microscopically. Human serum proteins were determined with immunoelectrophoresis. ${ }^{24,25}$. Serum of $0.04 \mathrm{ml}$ in each rabbit was placed on the strips of cellulose acetate membrane by special micropippetes, and following electrophoresis was performed by the electrophoretic apparatus from Jooko Sangyo Co. Ltd, Tokyo. It was run under the current of 0.5 milliamps per centimeter of membrane for an hour.

After the run, the precipitin reaction against anti-human serum rabbit serum (Behringwerke AG. Marburg. LAHN) was carried out on these strips which incubated for 48 hours at room temperature in liquid paraffin later.

The strips were thoroughly washed in water subsequently, stained by Ponsoux 3R for two minutes, and rinsed three times for 30-60 seconds each in fresh solution of 2 per cent acetic acid. The strips were dried and carefully examined for the precipitin lines.

\section{Results}

When one to $2 \%$ pontamine sky blue in Ringer's solution was introduced into the afferent lymphatic of the popliteal lymph node, serum obtained for 10 minutes after the introduction of dye showed blue coloration. After serum having been stained for 20 to 30 minutes, its color gradually faded away (Fig. 18).

The draining venous blood at 10 to 40 minutes after the introduction human 
gamma globulin was immunoelectrophoretically examined. The results are demonstrated in Fig. 1. The top figure shows the immunoelectrophoretic pattern with the sample taken before the introduction of human gamma globulin. The follownig 6 figures indicate the immunoeletrophoretic patterns with samples taken in every 10 minutes after the application of human gamma globulin. The precipitin lines appear in the immunoelectrophoretic figures with samples taken 30 minutes or later after the introduction of human gamma globulin.

At next stage, four folds diluted human whole serum was introduced to the lymph nodes and immunoelectrophoresis was performed on the serum in the draining venous blood versus anti-human serum rabbit serum. The results are shown in Fig.2. The top figure shows precipitin occurred between whole human serum and anti-human serum rabbit serum; the second shows the immunoelectrophoresis with rabbit serum obtained before the injection of human whole serum. The immunoelectrophoretic patterns with samples taken in every 10 minutes after the introduction of the human serum were demonstrated from the third down. The precipitin line due to albumin fraction of human serum vaguely appeared at 20 minutes after injection, which increased its intensity

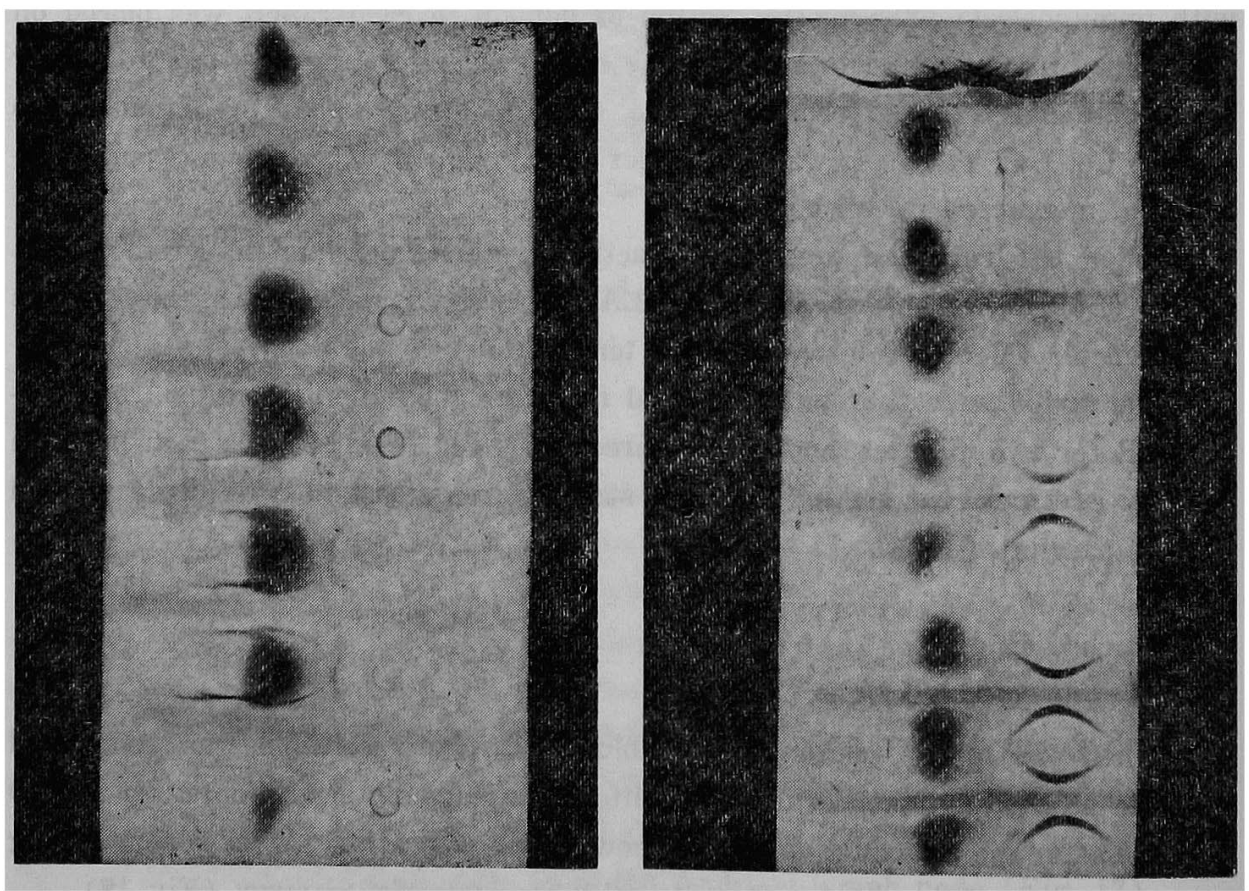

Fig. 1

Fig. 2 
during succeeding an hour. Globulin fraction of human serum appeared in the samples collected at 30 to 70 minutes after the injection.

4. The site of the exudation of blood vessel system of the rabbit popliteal lymph node

Materials and Methods

Albino rabbits weighing approximately $2.5 \mathrm{~kg}$ were used. Colloidal iron (Fesin) saline solution was injected into their femoral arteries under the ether anesthesia. Animals were sacrificed just after the injection and also after 10, 30 and 60 minutes. Their popliteal lymph nodes were excised and 10 micron sections were made in which iron was stained blue with potassium ferrocyanide an examined with a light microscope.

Results

When colloidal iron (Fesin) saline solution was injected into the rabbit popliteal lymph node, Fesin particles were found around the capillary networks of the peripheral parts of the lymphatic matrix (Fig. 21). After 10 minutes Fesin particles further increased (Fig. 22). After 30 to 60 minutes a lot of Fesin particles were seen from intermediate sinuses to medullary sinuses. However Fesin was never seen in the lymphatic matrix (Figs. 23 and 24).

5. The site of the fluid absorption of blood vessel system of the rabbit popliteal lymph nodes

Materials and Methods

Albino rabbits weighing approximately $2.5 \mathrm{~kg}$ were used. The afferent lymphatics of their popliteal lymph nodes were injected with $1 \mathrm{ml}$ of colloidal iron (Fesin) for 10 minutes with the same polyethylene catheter which was used in Experiment 1. These lymph nodes were removed 30 minutes after the injection, fixed in $10 \%$ formalin solution, embeded in paraffin and made to 3 to 5 micron thick sections. These sections were stanied for hematoxylin and eosin, and for iron.

Results

There was a majority of Fesin injected in the lymph sinus system, from 
marginal sinues to intermediate or medullary sinuses. However, a small amount of Fesin particles were found in the lymphatic matrix including reticular tissues and post-capillary venules (Fig.19). And Fesin particles were seen abundantly around the post-capillary venules. With careful observation of the post-capillary venules the particles of Fesin, which were homogenous or fine granular, were found in the lumens of the post-capillary venules and also in the interendothelial gaps (Fig. 20).

A large number of Fesin particles were found in the veins of medullary cords. The macrophages which took up Fesin particles were often seen.

On investigating the lymphatic parenchyme, Fesin injected lymph node showed the following pictures.

1) The lymphocytes were full in the lymphatic matrix of the lymph nodes. This picture was generally understood as the usual structure of the lymphoid tissue.

2) Most of the lymphocytes were eliminated from the lymphatic matrix. In such case, "incomplete sinus" like structure appeared in the lymphatic matrix, and also the accumulation of lymphocytes were present around the post-capillary venules.

3) The lymphocytes were markedly eliminated from the lymphatic matrix and whole area of the lymphatic matrix was almost composed of the reticular frame-work only.

When the areas of the presence of Fesin were observed, Fesin particles were seen abundantly in the regions where lymphocytes were full in the lymphatic matrix, while they were very scanty or none in the regions where lymyphocytes were eliminated from the lymphatic matrix.

\section{DISCUSSION}

With the recent advance in immunopathology, the necessity has risen to understand dynamic aspects of the structure and function of lymph nodes as an antibody producing organ. Lymph nodes, as mentioned before, are thought to be in the immature state of differentiation as an organ. They, therefore, show morphological deviation either in physiologic or in pathologic conditions. Careful attention must be paid not only to the lymph flow but also to the blood flow in lymph nodes to understand their complicate structures and functions.

In most of works of other investigators on lymph nodes, however, the emphasis has been placed on the behaviors of lymph nodes to which lymph flows from various kinds of lesions. Therefore, it has been stressed that the lymphat- 
ics or the lymph sinus system would play a major role to define the reaction of a lymph node.

Many investigators have studied on the blood vessel system of the lymph node (Schulze (1925), ${ }^{35}$ Baum (1926), ${ }^{26}$ Heudorfer (1927), ${ }^{27}$ Hellman (1930), ${ }^{28}$ Kihara (1954), 29 Horii (1963), ,30 Ono (1963), 31,32 Nakagawa (1937), ${ }^{33}$ Nitta $\left.(1955-1956)^{34}\right)$. They have dealt with particularly the vascular architecture within the secondary nodules and its alteration in connection with folliclar activity. Although Gowans (1964) ${ }^{36}$ reported on the ultrastructure of post-capillary venules, most of other investigators have mainly put importance on changes occurred in the arterial side of the vascular system, so that, a number of problems of the venous side have been left unknown.

The structure and function of microcirculatory units including arterioles, capillaries and venules of lymph node, especially specific function of each different unit and the interrelation between them should be clearly explained to understand the structure and function of lymph nodes. No systematic works have been reported about these problems in the past.

Through a series of experiments mentioned above, the author tried to clarify the distribution of blood vessel system within the lymph node and also the interrelation between the lymphatics and the blood vessels. The function of lymph node with speical reference to the fluid exchange is discussed in the following three separate sections.

1) The microcirculatory architectures of the rabbit popliteal lymph node.

Comparing the total volume of arterial system with that of venous system in lymph nodes, even if taking into consideration of high endothelial cells of postcapillary venules, the arterial system is much smaller in volume than the venous system. This finding suggests that venous system is able to absorb the fluid within lymph nodes under certain conditions.

The capillary networks are formed in the area of the peripheral lymphatic matrix. Generally the fluid and various substances reach to the intermediate sinuses through the marginal sinuses by the route of the efferent lymphatics. So, it seems that noxious stimuli could influence not only to the capillary networks but also to the local architecture of the lymphatic matrix.

Concerning the field where secondary nodules are formed, it seems that the nodules are found in the peripheral matrix, especially at the corner of the lymphatic matrix where the capillary networks are formed.

The post-capillary venule (P.C.V.) is a characteristic vessel of lymph node. A fine study on the post-capillary venule at light microscopic level was reported by Schulze (1925).35 In the field of the immunobiology, one's attention began 
tending to post-capillary venule after the work of Gowans and his group (1964). ${ }^{36}$ The ultrastructural studies on P.C.V. were reported by Marchesi and Gowans $(1964),{ }^{37}$ Sugimura et al. (1964),,$^{38}$ Mikata and Niki (1966).22

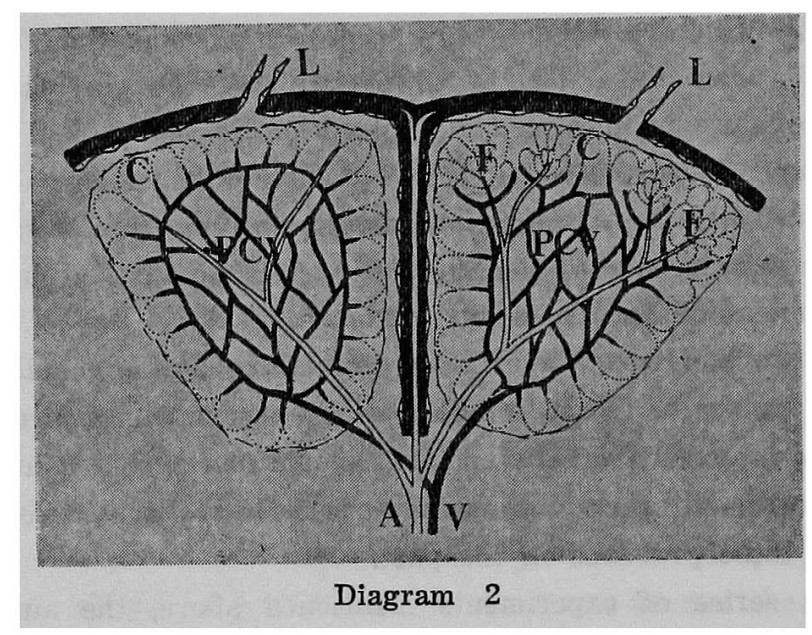

The concentration of post-capillary venule plexuses which are formed in the lymphatic matrix is in inverse proportion to numbers of secondary nodules.

2) The presence of the direct passage from lymph flow to blood flow within the rabbit popliteal lymph node.

On the basis of the characteristic vascular architecture of the lymph node it was speculated that the venous system carries out the absorbed fluid in the lymph node. The first step to determine that problem is to search for the presence of the direct passage from lymph flow to blood flow within the lymph node. A number of researchers are greatly interested in this problem and various hypotheses have been proposed. Some of the previous researchers suggested the presence of the direct communications from lymph flow to blood flow, and asserted to find such phenomenon. (Schulze (1925), ${ }^{35}$ Yoffey (1956), ${ }^{39}$ Shanbron et al. (1959),40 Pressman et al. (1961-1962), 41,43 Mayerson (1962),42 Bron et al. (1963),44 Pentecost et al. (1966), ${ }^{45}$ Borodin et al. (1966), ${ }^{46}$ Rusznyak et al. $\left.(1967)^{47}\right)$. However the direct passage has not been proved under physiologic condition.

The author, as mentioned above, demonstrated immunoelectrophoretically that various substances injected into the afferent lymphatic of the rabbit popliteal lymph nodes were found in the venous blood drained from these lymph nodes. Immunoelectrohoresis is a sensitive and precise method of detection of antigen 
or antibody by the application of antigen-antibody reaction.

The fact that an example of heterologus proteins, especially gamma globulin passes from lymph flow to blood flow within lymph node suggests that antibody produced in the lymph node could rapidly be absorbed into blood flow. This speculation may give a great clue to make clear the mechanism of immunity (Diag. 3 ).

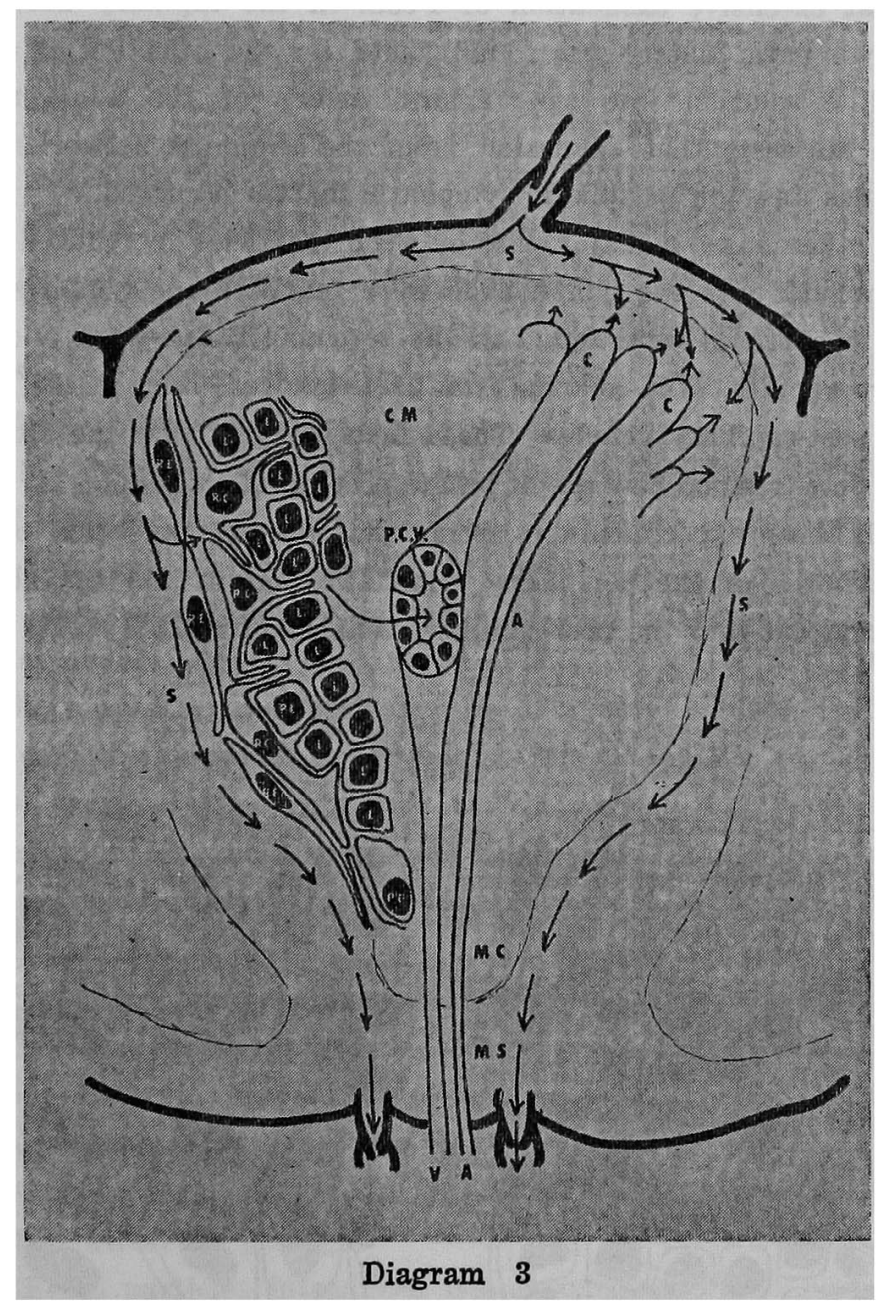

Albumin (molecular weight 69,000) appeared earlier in the draining venous blood than globulin, (molecular weight 160,000). This suggests that molecular weight of substances introduced regulates the rate of the passage.

At a rough order estimation, one fourth or fifth of introduced protein passes 
from lymph flow into blood flow during early 30 minutes

3) The site of exudation and absorption within the rabbit popliteal lymph node.

For the detection of the direct passage of proteins from lymph flow to blood flow within the lymph node, the site of the passage must be examined. It was observed that extensive exsudation of Fesin in the capillary networks of the peripheral lymphatic matrix was found just after the injection of colloidal iron (Fesin) saline solution into the femoral artery of the adult rabbit. This phenomenon suggests that exudation from the capillary networks of the secondary nodules and the peripheral lymphatic matrix occurred.

On the other hand, a major part of Fesin particles introduced through the afferent lymphatic into the lymph node were found in the lymph sinus system. Rest of Fesin particles were found in the reticular frame-work and around the post-capillary venules. The colloidal-iron particles were seen in the lumen or the wall of the post-capillary venules. These facts suggest that the site of passage from lymph flow to blood flow might be the post-capillary venule.

Through these experiments it seems that plasma exudation occurs in the capillary networks of the peripheral lymphatic matrix and the absorbed fluid may be carried out into the post-capillary venules (Diag. 3 ).

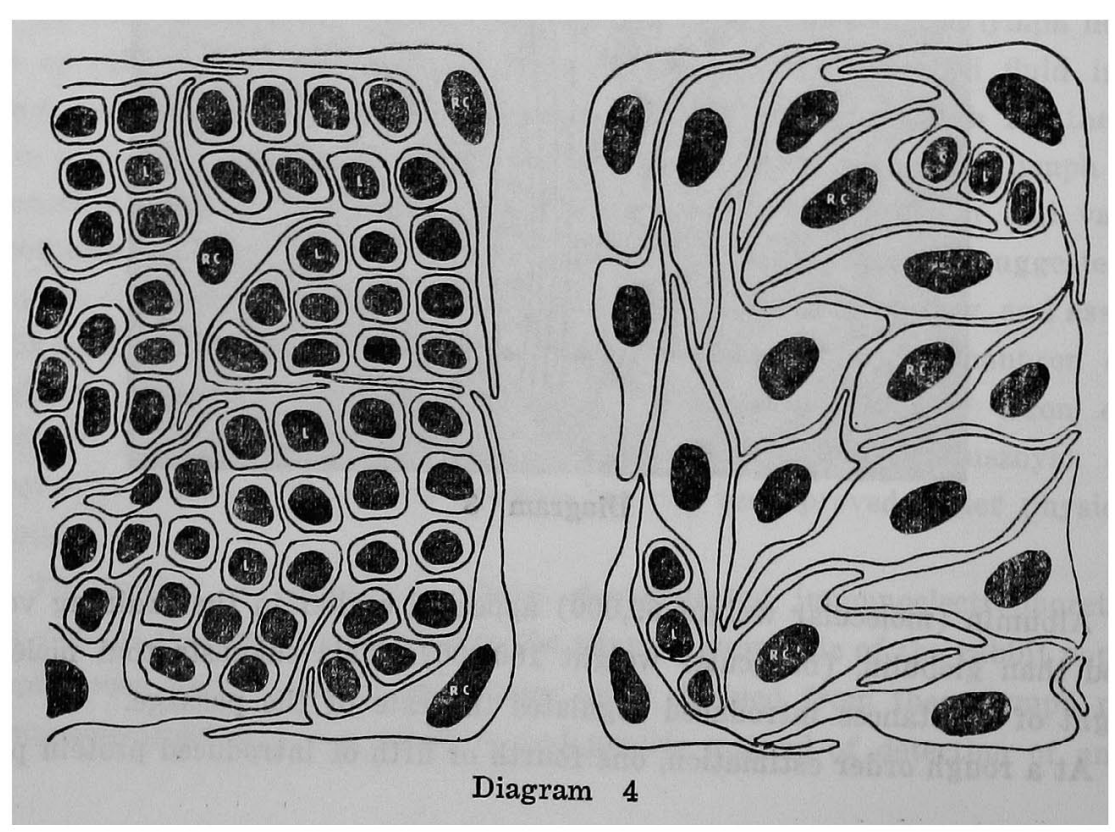


On considering the concentrations of lymphocytes and Fesin particles wihch are in inverse proportion, lymphocytes appear to be expelled in accordance with compression of frame-works of reticular cells by various lymphgenous stimuli. The compressed and narrow spaces between the reticular cells play an important role in the passage of the fluid. The movements of the reticular framework must have a great influence upon the absorption of the fluid (Diag.4).

\section{SUMMARY}

In this paper the characteristics of vascular system of the rabbit popliteal lymph nodes, especially the function of post-capillary venules was investigated. The presence of direct passage from lymph flow to blood flow within lymph nodes was proved on various substances of macromolecules. The results are as follows:

1. The most characteristic feature of the microcirculatory architecture of the rabbit popliteal lymph nodes is the presence of the post-capillary venule which was named after Schulze.

2. The post-capillary venules form complicated venous plexuses in the cortical lymphatic matrix.

3. The post-capillary venules does not appear in the embryonic stage and is able to be observed on the second day after birth.

4. The secondary nodules are formed in the area of the peripheral lymphatic matrix where capillary networks face the lymphatic sinuses.

5. The capillary networks in secondary nodules and the venous plexuses of post-capillary venules in the lymphatic matrix form a functional unit of the vascular architecture of lymph nodes, and these two subunits, i.e. the secondary nodules and the venous plexuses react antagonistically to various stimmulations given to lymph nodes.

6. Pontamin sky blue in Ringer's solution, human whole serum, human gamma globulin introduced through the catheter into the afferent lymphatics of the rabbit popliteal lymph nodes were detected immunoelectrophoretically in the blood plasma obtained from vein draining from the lymph node.

Molecular weight of substances introduced is the important factor for determining the rate of the passage.

7. The Fesin particles introduced lymphogenously into lymph nodes were found in the lumen or the wall of the post-capillary venules.

8. From these facts, it is concluded that various substances would be able to pass from lymphatics into veins in lymph nodes in physiologic conditions and that the site of passage from lymph flow into blood flow i.e. the site of absorption of the fluid is the post-capillary venule. 
9. The movement of reticular frame-work has a great influence upon the absorption of the fluid in lymph nodes.

\section{ACKNOWLEDGEMENT}

The author's grateful acknowledgement is made to Prof. Dr. Keizo Kageyama for his kind and proper guidance. The helpful interest of Drs. Hisao Yamaguchi, Kensuke Baba, Hiroshi Takeuchi and others is acknowledged with thanks. I am indebted to Miss Michiko Iwahashi for her technical assistance. The photographs were prepared by Mr. Shin Takeichi.

\section{REFERENCES}

1. Ando, S.: Systemic studies on the development of human and mammal lymph nodes. Kaibogaku Zasshi, 3: 761-791, 1930. (in Japanese)

2. Iijima, S.: Biological significance of the lymph node. Saishin Igaku, 21: 11421144, 1966. (in Japanese)

3. Kageyama, K., Shimizu, K., Saito, T., Yamaguchi, H., and Tozawa, H.: Dynamicopathological studies on the circulatory disturbances in the microcirculatory region. I. Circulatory disturbances in local anaphylaxis and by other several vaso-active agents. Tr. Soc. Path. Jap., 50: 226-227, 1961. (in Japanese)

4. Kageyama, K., Saito, T., Yamaguchi, H., and Tozawa, H.: Experimental studies on the microcirculatory disturbances in local anaphylaxis. Jap. J. A.ller., 10: 591, 1961. (in Japanese)

5. Saito, T.: Microcirculatory disturbances in local allergy. Keio J. Med., 12: 9-16, 1961.

6. Kageyama, K.: Dynamicopathological studies on the circulatory disturbances in the microcirculatory region. 1) Acta Path. Jap., 13, 209-211, 1963, 2) SaishinIgaku, 18: 1448-1453, 1963. (in Japanese)

7. Yamaguchi, H., Fukuda, J., Saito, T., Mikata, A., and Kageyama, K.: Dynamicopathological studies on the circulatory disturbances in the microcirculatory region. II. On the leukocyte sticking and emigration. Tr. Soc. Path. Jap., 52 : 122-123, 1963. (in Japanese)

8. Yamaguchi, H., Kageyama, K., Fukuda, J., and Ohtashiro, N.: Dynamicopathological studies on the circulatory disturbances in the microcirculatory region. III. On the viscosity of acid mucopolysaccharies in microcirulatory disturbances. J. Jap. Colle. Angiol., 4: 122-124, 1964. (in Japanese)

9. Yamaguchi, H.: Studies on the viscosity of acid mucopolysaccharides in peripheral circulatory disturbances. Keio J. Med., 13: 43-58, 1964.

10. Kageyama, K., Yamaguchi, H., Fukuda, J., and Kasahara, M.: Dynamicopathological studies on the circulatory disturbances in the microcirculatory region. IV. On the so-called tuberculin type hypersensitivity in guinea pig mesentery. Tr. Soc. Path. Jap., 53: 97-98, 1964. (in Japanese)

11. Yamaguchi, H., Fukuda, J., Ohtani, T., and Kageyama, K.: Microcirculation in pathological conditions. J. Jap. Colle. Angiol., 5: 87-91, 1965.

12. Kageyama, K., Yamaguchi, H., and Fulkuda, J.: Dynamicopathological studies on the circulatory disturbances in the microcirculatory region. V. On the so-called tuberculin type hypersensitivity in guinea pig mesentery and omentum. Tr. Soc. 
Path. Jap., 54: 91-92, 1965.

13. Kageyama, K., Yamaguchi, H., Fukuda, J., Mikata, A., and Iwasaki, R.: The dynamic behaviours of the microcirculatory region observed on immediate and delayed type of hypersensitivity. Jap. J. Aller., 15: 337, 1966. (in Japanese)

14. Fukuda, J.: Observation techniques on the microcirculation of the living guinea pig mesentery. Igaku-no-Ayumi, 57: 237-241, 1966. (in Japanese)

15. Yamaguchi, H.: Studies on the microcirculation in pathological conditions. Ibid, 57: 272-276, 1966. (in Japanese)

16. Kageyama, K. and Yamaguchi, H.: Peripheral circulation in pathological conditions. Peripheral circulation and its pathological physiology, 157-164, Todai-Shuppan-Kai, Tokyo, 1967. (in Japanese)

17. Ohtani, T., Watanabe, K., and Kageyama, K.: Dynamicopathological studies on the circulatory disturbances in the microcirculatory region. VI. Enzyme-histochemical studies in the delayed hypersensitivity experimentally provoked in the guinea pig peritoneal cavity. Proc. Jap. Soc. R.E.S., 6: 131, 1966. (in Japanese)

18. Kageyama, K., Mikata, A., Yamaguchi, H., Fukuda, J., and Iwasaki, R.: Dynamicopathological studies on the delayed type hypersensitivity, J. Clin. Sci., 2: 801-808, 1966. (in Japanese)

19. Kageyama, K.: Reactions of the lymph node as an organ gainst various acute stimulations. 1) Tr. Soc. Path. Jap. 54 (Sup.) : 378-383, 1965. (in Japanese); 2) Acta Path. Jap., 17: 240-251, 1967.

20. Kageyama, K., Yamaguchi, H., Mikata, A., and Fukuda, J.: Studies on the microcirculation of the lymph node. Igaku-No-Ayumi, 57: 353-358, 1966. (in Japanese)

21. Yamaguchi, H. and Fukuda, J.: Vascular architecture of the rabbit lymph node and its functional significance. Saishin-Igaku, 21: 1157-1165, 1966. (in Japanese)

22. Mikata, A. and Niki, R.: Ultrastructure of the vessels in the mouse lymph node with special reference to the post-capillary venules. Saishin-Igaku, 21: 1145-1156, 1966. (in Japanese)

23. Watanabe, K. and Ohtani, T.: Enzyme histochemical observation of early changes of lymph nodes under Proteus endotoxin stimulation. Saishin-Igaku, 21 : 1190-1198, 1966. (in Japanese)

24. Ogawa, Y.: Cellulose acetate electrophoretic techniques, Jap. J. Clin. Path. Sup., 11: 46-63, 1966.

25. Kohn, J.: An immunoelectrophoretic technique. Nature, 180: 986-987, 1957.

26. Baum, H.: Die Benennung der Lymphknoten, Anat. Anz., 61: 39-42, 1927.

27. Heudorfer, K.: Utber den Bau der Lymphdrüsen, Z. Anat., 61: 365-401, 1927.

28. Hellman, T.: Die Lymphknötchen und die Lymphknoten. Möllendorff's Handbuch VI/1: 282-396, 1930.

29. Kihara, T.: The distribution and development of the lymphatic tissue. Symposium on Hematology (VI) : 1-44, Nagai-Shoten, Osaka, 1954. (in Japanese)

30. Horii, I. and Kawakami, Y.: The distribution and development of the lymph node. Nihon-Ketsuekigaku-Zensho (Handbook of Hematology) I: 797-822, Maruzen, Tokyo, 1965. (in Japanese)

31. Ono, K.: The structure of the lymph node. Ibid. I: 823-839, 1963. (in Japanese)

32. Ono, K. und Miyazaki, T.: Uber die Beziehungen zwischen den Lymphknötchen und den arteriellen Blutgefäßen. Tr. Soc. Path. Jap. 26: 278-288, 1936.

33. Nakagawa, T.: Histologische Einteilung der Lymphknötchenformen und deren Wechselbeziehungen. Jap. J. Med. Sci., (V). Pathology 1(3) : 119-150, 1938.

34. Nitta, Y.: Stereographic study of the canalicular system of lymph nodes by acryric casting. I. On the canalicular system of the lymph nodes of the rabbit. 
Acta Sch. Med. Gifu, 2: 433-448, 1954 5. (in Japanese)

35. Schulze, W.: Untersuchungen über die Capillaren und post-capillären Venen Lymphatischer Organe. Z. Anat. 76: 421-462, 1925.

36. Gowans, J. L. and Knight, E. J.: The route of re-circulation of lymphocytes in the rat. Proc. Roy. Soc. (Ser. B) 159: 257-282, 1963 4.

37. Marchesi, V. T. and Gowans, J. L.: The migration of lymphocytes through endothelium of venules in lymph node an electron microscope study. Proc. Roy. Soc. (Ser. B) 159: 283-290, 1963 4.

38. Sugimura, M. et al.: Fine structure of post-capillary venules in mouse lymph nodes. Jap. J. Vet. Res., 12: 83-90, 1964.

39. Yoffey, J. M. and Courtice, F. C.: Lymphatics, lymph and lymphoid tissue. 2nd Ed., Edward Arnold LTD. London, 1956.

40. Shanbron, E. and Zheutlin, N.: Radiographic Studies of the lymphatic system. Arch. Int. Med., 104: 589-593, 1959.

41. Pressinan, J. J., Simon, M. B.: Experimental evidence of direct communications between lymph nodes and veins. Surg. Gyne. Obst., 113: 537-541, 1961.

42. Mayerson, H. S., Patterson, R. M., McKee, A., LeBrie, S. J., and Mayerson, P.: Permeability of lymphatic vessels, Am. J. Physiol., 203: 98-106, 1962.

43. Pressman, J. J., Siomn, M. B., Hand, K., and Miller, J.: Passage of fluids, cells, and bacteria via direct communications between lymph nodes and veins. Surg. Gyne. Obst., 114: 207-214, 1962.

44. Bron, K. M., Baum, S., and Abrams, H. L.: Oil embolism in lymphangiography. Incidence, Manifestations, and Mechanism. Radiol., 80: 194-202, 1963.

45. Penteco-t, B. L., Burn, J. I., Daies, A. J., and Calnan, J. S.: A Quantitative study of lymphovenous communications in the dog. Brit. J. Surg., 53: 630-634, 1966.

46. Borodin, Y. I. and Tomehik, G. V.: Functional relationships between blood vessels and lymphatic sinuses normally and during experimental disturbances of blood and lymph circulation. Fed. Proc., 25: 778-781, 1966.

47. Rusznyak, I., Foldi, M., and Szabo, G.: Lymphatics and lymph circulation, physiology and pathology. Oxford, Pergamon Press, 1967. 
Fig. 3. Vascular architecture of the rabbit lymph node: An artery (A) runs fairly straight in the upper part of the picture and veins (V) are much thicker than arteries.

Fig. 4. Vascular pattern of the peripheral area of the lymphatic matrix: An arteriole (Ao) communicate with post-capillary venules through complicate networks of capillaries.

Fig. 5. Vascular pattern of lymphatic matrix where capillaries face the lymphatic sinuses: Complicate networks of the capillaries (C) are seen as in Fig. 4.

Fig. 6. Vascular pattern of secondary nodule: An arteriole (Ao) enters a secondary nodule from the pole of the medullary side.

Fig. 7. Vascular pattern of a secondary nodule: An arteriole (Ao) reaches capillary network which shows the glomerulus like pattern and goes the post-capillary venule around the secondary nodule.

Fig. 8. Post-capillary venules of an adult rabbit popliteal lymph node: The postcapillary venule has tall endothelial cells and its lumen is very narrow. The lymphocytes are trapped within the wall.

Fig. 9. The general pattern of the vascular architecture of the lymph node: V: vein, F: secondary nodule. (Unstained thick section, $300 \mu$ )

Fig. 10. H-E staining $(10 \mu)$ of Fig. 9.

Fig. 11. This photograph shows the co-relations of all parts of the vascular architecture of the lymph node. (Unstained thick section, $300 \mu$ )

Fig. 12. H-E. staining $(10 \mu)$ of Fig. 11.

Fig. 13. Post-capillary venular plexuses: The post-capillary venules form the venous plexuses which occupies widely the cortical matrix. The venous plexuses are continuous to the venules (V).

Fig. 14. H-E staining $(10 \mu)$ of Fig. 13.

Fig. 15. The lymph node of the 25th day rabbit fetus: The post-capillary venules are not yet seen.

Fig. 16. The lymph node of the 2nd day new-born rabbit: Some of the blood vesels of cortical matrix have somewhat high cuboidal endothelia.

Fig. 17. A rabbit popliteal lymph node is isolated. The catheter(A) is inserted into the afferent lymphatic (white arrow). A efferent vein is cannulated by the catheter(B) indicated with blue arrow to collect draing venous blood.

Fig. 18. Samples of the sera obtained draing venous blood after the administration of pontamine sky blue.

No. 1 shows the sample before administration.

No. 2 shows 10 minute sample after administration.

No. 3 shows 20 minute sample after administration.

No. 4 shows 30 minute sample after administration.

Fig. 19. The distribution of colloidal iron (Fesin) injected into the afferent lymphatic. The section is stained for the iron.

Fig. 20. Fesin particles injected into the afferent lymphatic were demonstrated in the lumen and in the wall of the post-capillary venule.

Fig. 21. Fesin introduced into the femoral artery of the rabbit are seen around the capillary networks of the peripheral areas of the lymphatic matrix of the node 10-20 minutes after the introduction.

Fig. 23-24. After 30-60 minutes of the introduction deposits of Fesin are further increased. 


\section{PLATE 1}

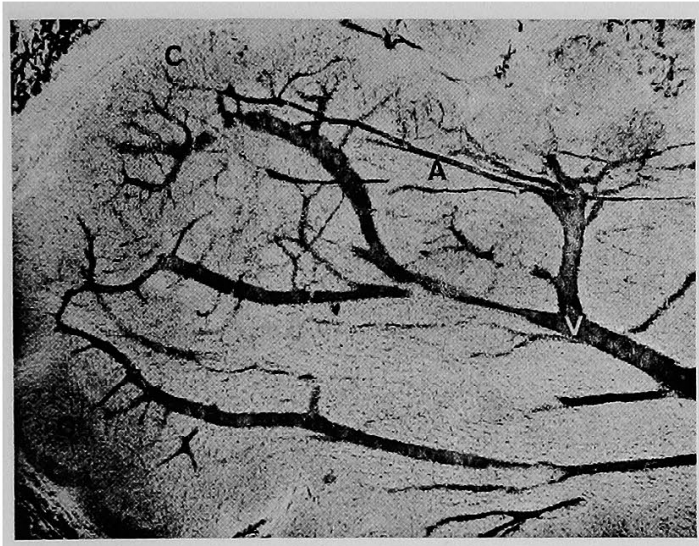

Fig. 3

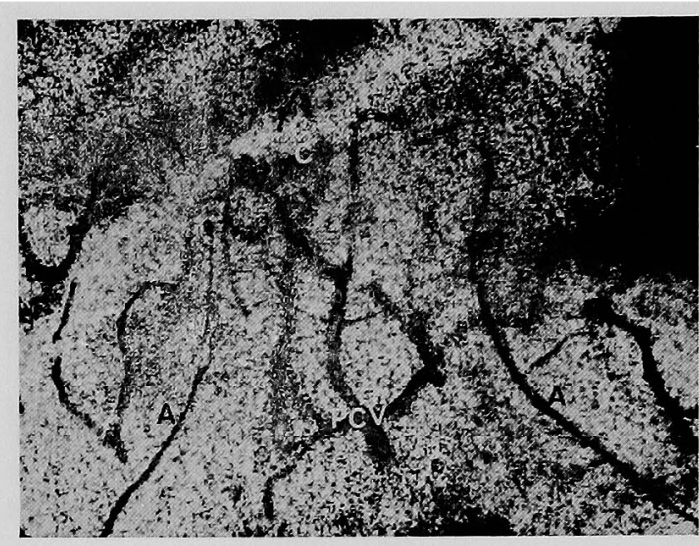

Fig. 4

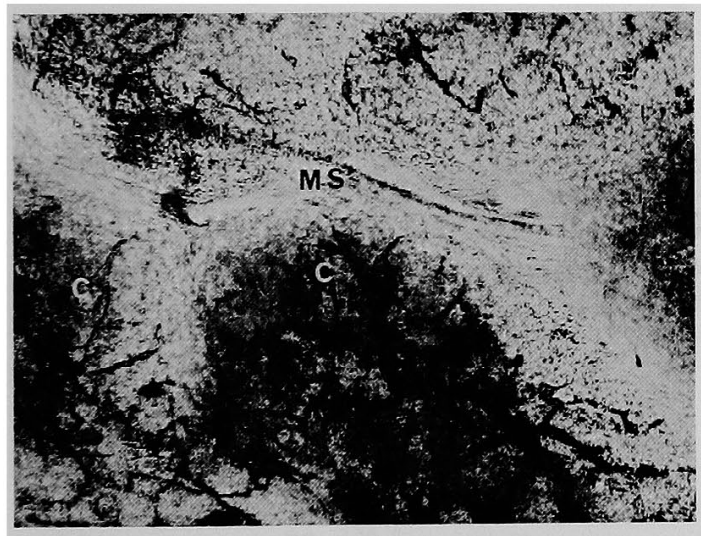

Fig. 5

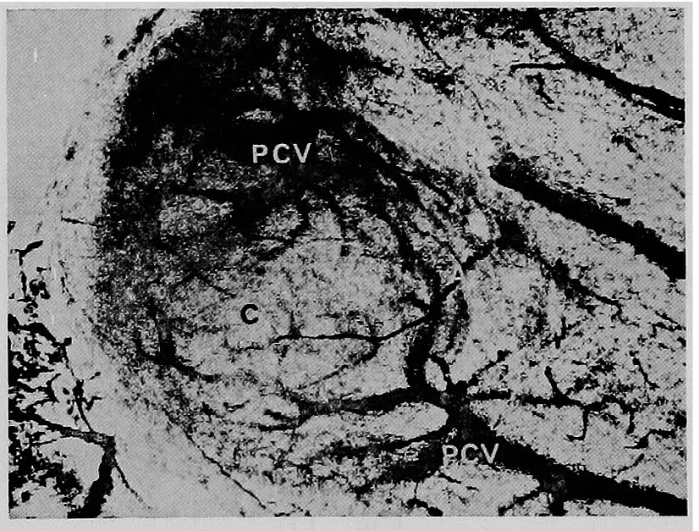

Fig. 6

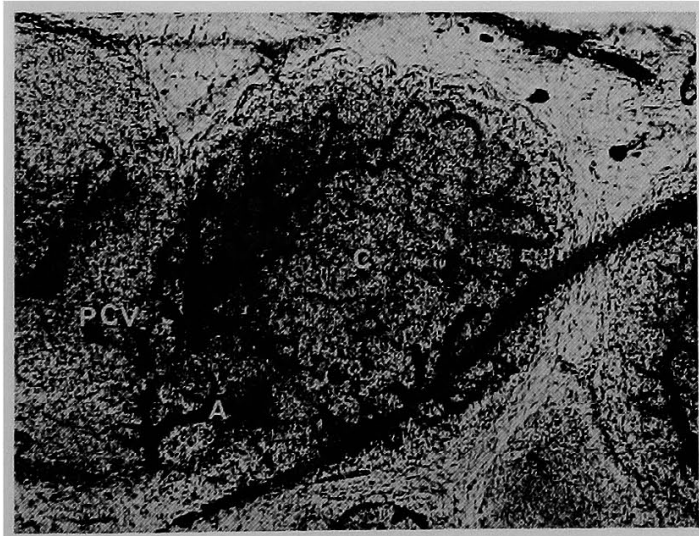

Fig. 7

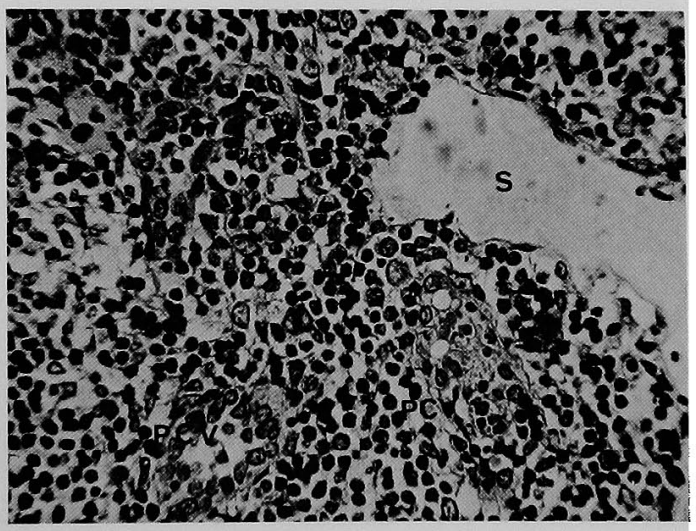

Fig. 8 
PLATE 2

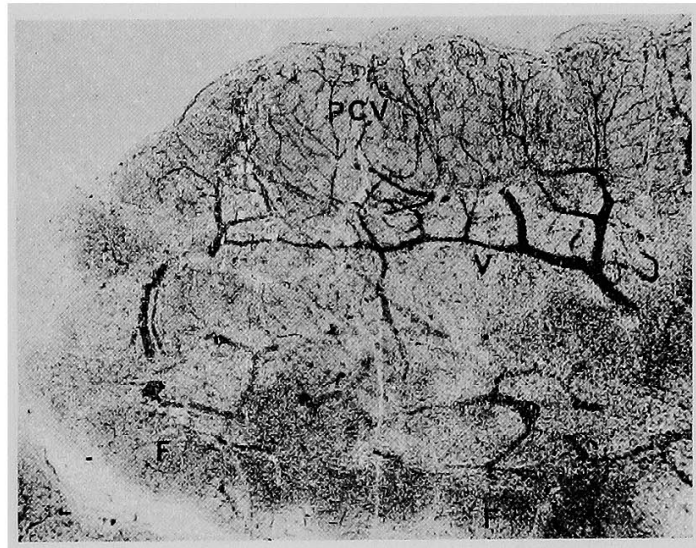

Fig. 9

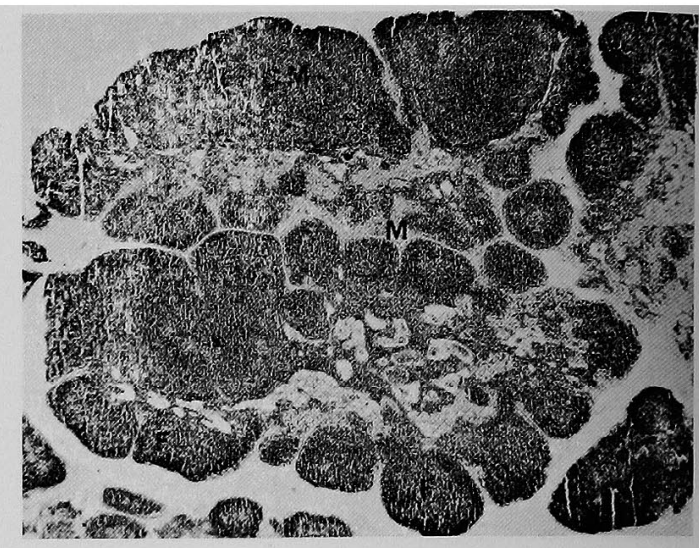

Fig. 10

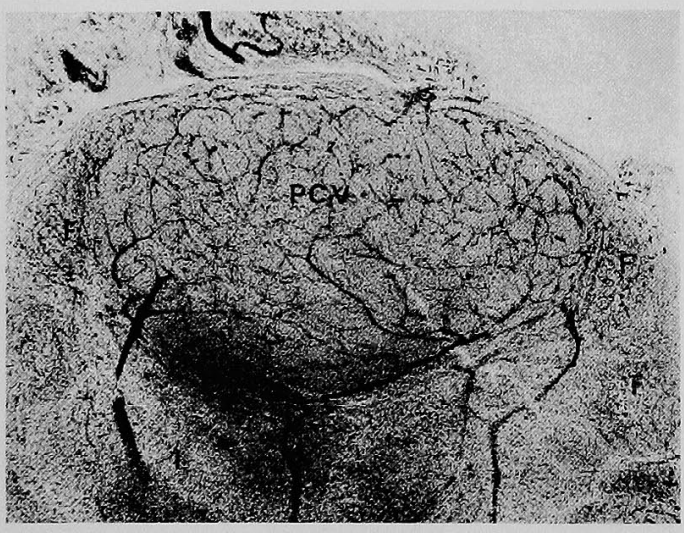

Fig. 11

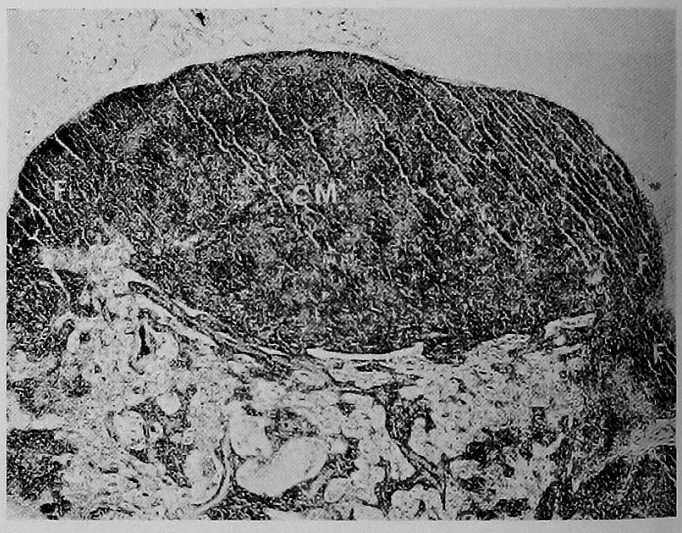

Fig. 12

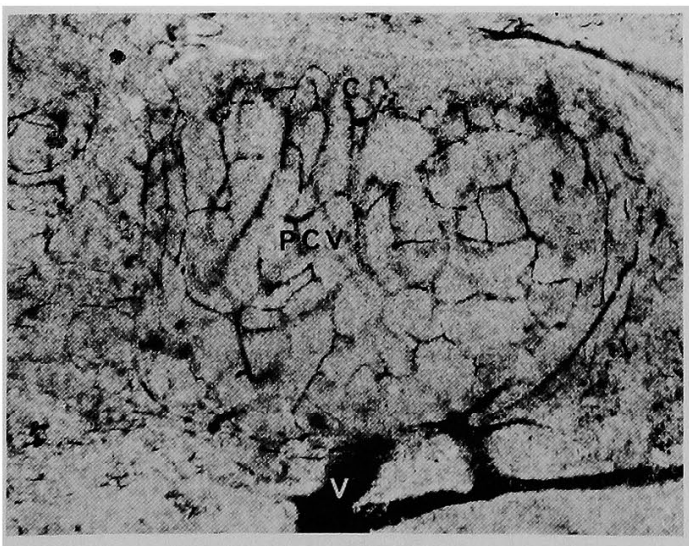

Fig. 13

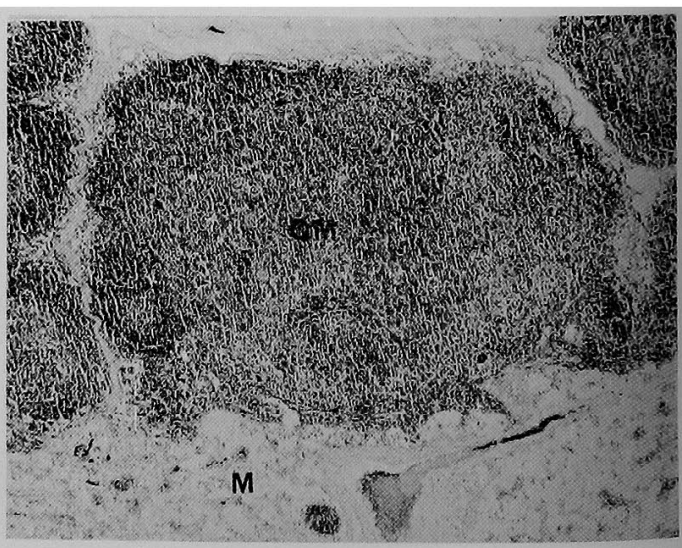

Fig. 14 
PLATE 3

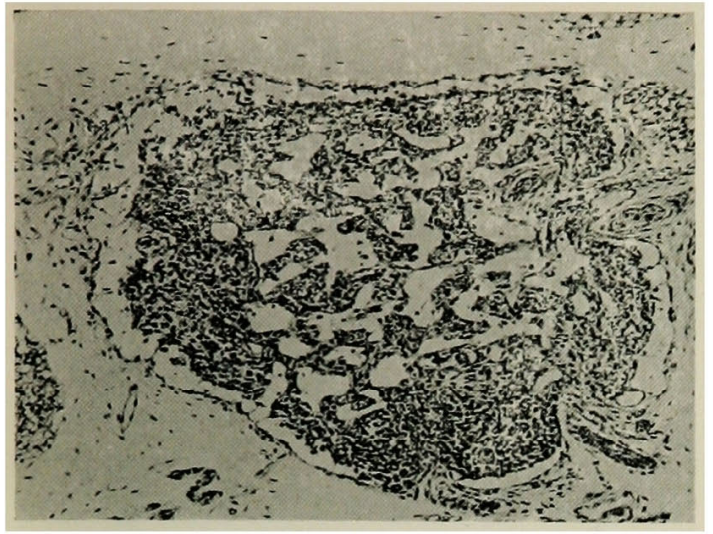

Fig. 15

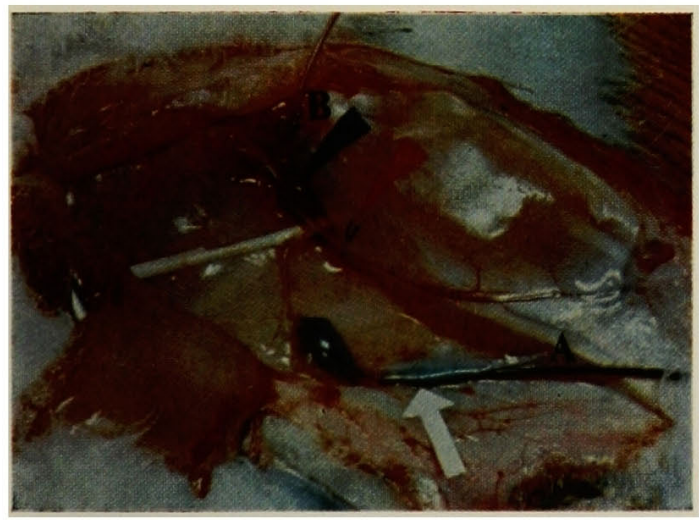

Fig. 17

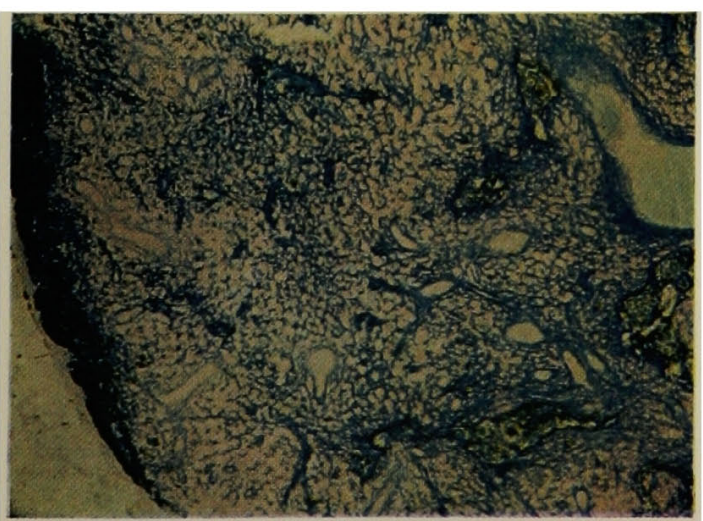

Fig. 19

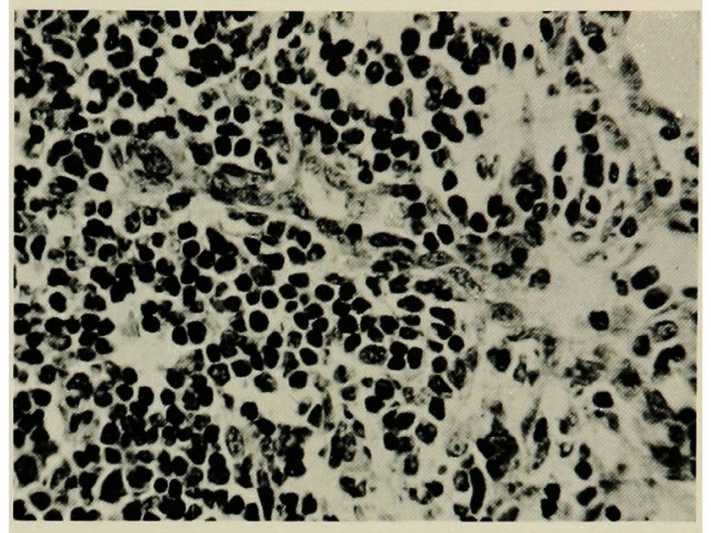

Fig. 16

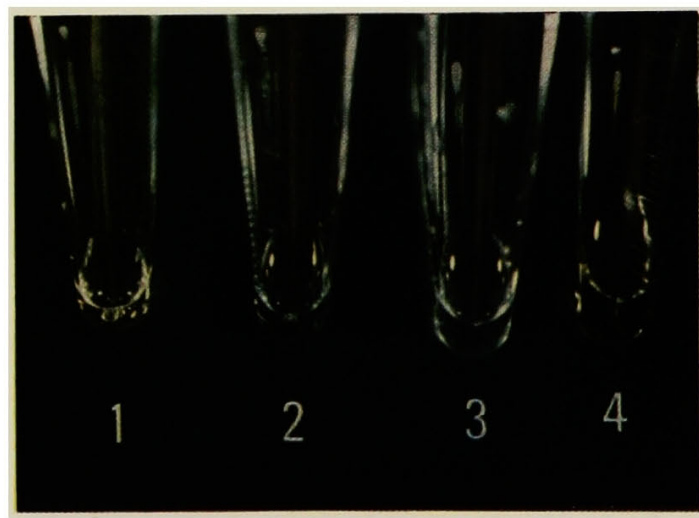

Fig. 18

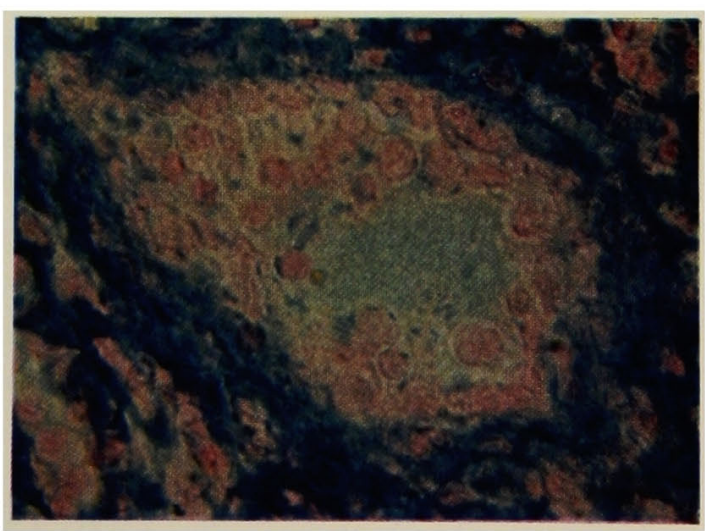

Fig. 20 
PLATE 4

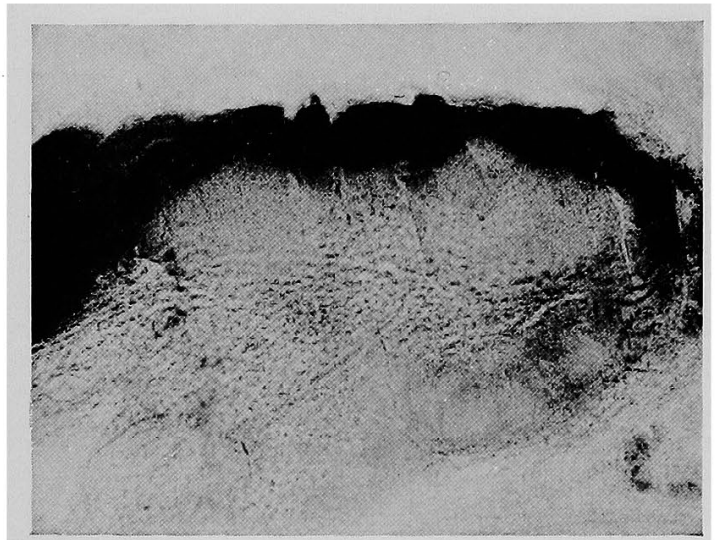

Fig. 21

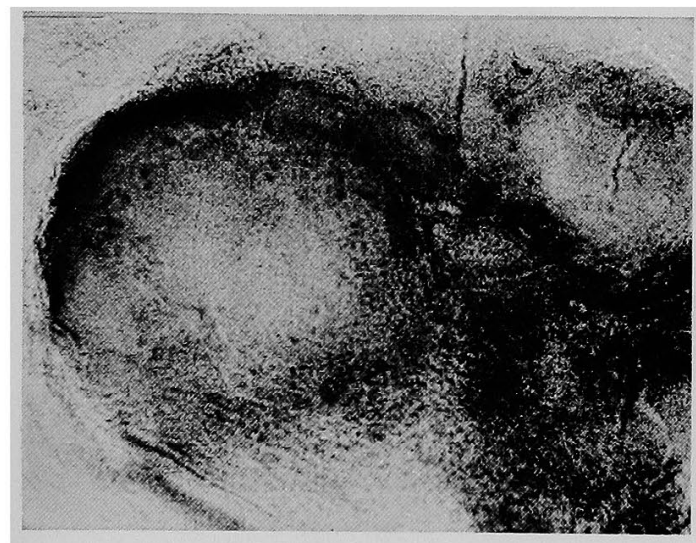

Fig. 23

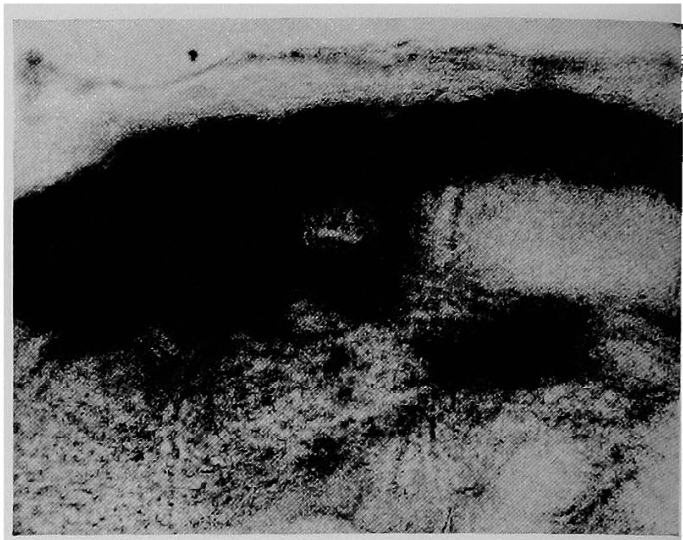

Fig. 22

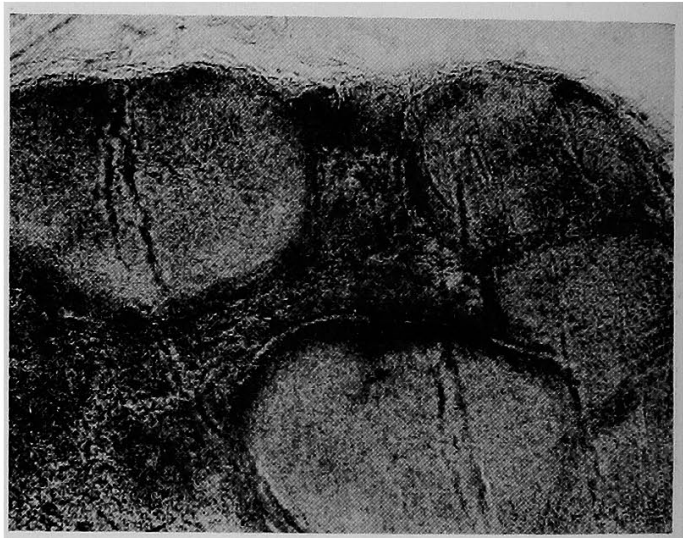

Fig. 24

J. FUKUDA 